Brit. J. industr. Med., 1963, $20,95$.

\title{
A PRELIMINARY STUDY OF SOME HEALTH HAZARDS IN THE PLASMA JET PROCESS
}

\author{
BY \\ D. E. HICKISH and P. J. R. CHALLEN \\ From the Occupational Hygiene Service, Slough, Bucks.
}

(RECEIVED FOR PUBLICATION AUGUST 27, 1962)

\begin{abstract}
A brief technical description is given of the plasma jet process, and reference is made to its likely practical applications in industry. An opportunity has been taken during experiments with a prototype plasma jet to assess some of the health hazards which might arise from these industrial applications and to indicate the type of precautions which should be observed in practice.

Measurement and analysis of the noise emitted during the operation of a jet showed that the sound intensities ranged from 79.5 to $90.5 \mathrm{~dB}$ (re 0.0002 dynes $/ \mathrm{cm}^{2}$ ) per octave band between 300 and 10,000 cycles/second. Three male volunteers exposed to the noise for a period of one hour were subsequently found to have a mean temporary threshold shift of $19 \mathrm{~dB}$ at 4,000 cycles/second.

Air sampling and analysis for ozone and nitrogen dioxide in the near vicinity of the jet gave a negative result for the former substance but demonstrated that the latter contaminant was present in concentrations ranging from 0.1 to 9.6 p.p.m.
\end{abstract}

Early in 1960 two male research scientists attended the Central Clinic of the Slough Industrial Health Service complaining of deafness. During the previous four days they had been employed in a member firm on experiments with a plasma jet torch and they mentioned that the process was extremely noisy. Subsequently we visited the firm to see the process in operation and, as it seemed very likely that the noise emitted by the process was of such intensity and pitch that it could be hazardous to hearing, we decided to carry out an environmental and clinical study. An odour similar to that of ozone was detected in the near vicinity of the operation, which we attributed to the action upon air of the intense ultraviolet radiation being emitted, and consequently we included an assessment of this possible hazard in our programme of study.

\section{The Plasma Jet Process}

The plasma jet process has come into prominence in the U.S.A. during the past four to five years because the plasma torch offers tremendous advantages over conventional chemical flames for many welding applications, and the process is now attracting increasing attention in this country.
However, considerable work on the production of plasmas, using the electric arc as the heat source, was accomplished in the early part of the present century. A plasma results from the electric heating of a gas to a temperature at which its molecules become ionized atoms possessing high energy. Plasma is considered to be a fourth state of matter, i.e. neither gas, liquid, nor solid.

Until the period immediately subsequent to the second world war, there was little demand for a heat source more intense than the oxyacetylene flame. The advent of gas turbine and rocket engines, with the accompanying demand for better materials and greater knowledge of high-temperature reactions and processes, created a critical concern for high-temperature technology and a renewed interest in the plasma field.

There are various designs of plasma equipment and plasma torches, but in essence they all operate in a similar fashion. The basic principle of the process is that an intense jet of electrons and ionized gas particles is forced to issue through a very narrow orifice. The jet is formed by the passage of a gas such as argon, helium, or hydrogen through an electric arc which is struck between two electrodes in a confined space, the gas being heated to arc 


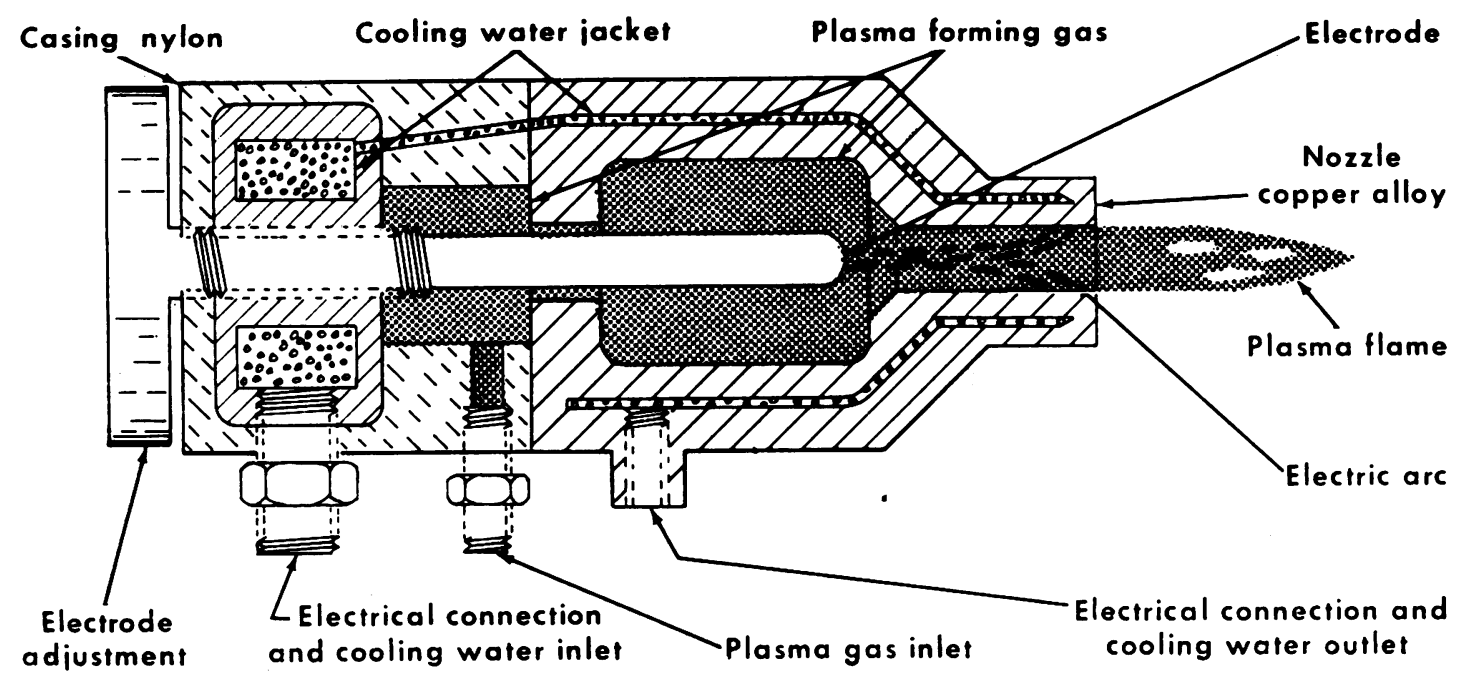

FIG. 1.-Plasma flame torch.

temperature. The emitted plasma flame can reach a temperature of $60,000{ }^{\circ} \mathrm{F}$., and with its application all materials can be melted and even vaporized. The plasma jet is not only ejected through the torch nozzle at very high temperatures but also at very high speeds; jet velocities of well over $20,000 \mathrm{ft}$. per second are possible. A sketch of a typical plasma flame torch is shown in Fig. 1 (Browning, 1959).

There are two basic types of the modern plasma jet device, namely the 'transferred arc' and the 'nontransferred arc' torches, and these are illustrated diagrammatically in Fig. 2 (Gage, 1959). In the former type the gas and arc after leaving the nozzle continue to the work, and this torch is used for

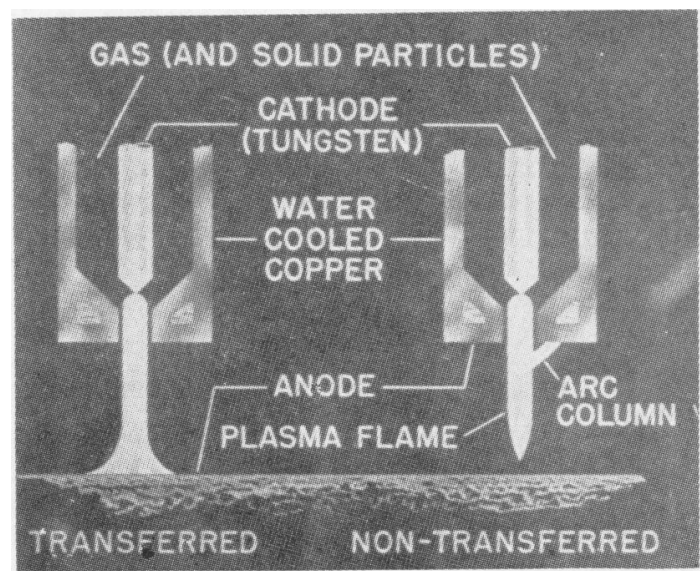

FIG. 2.-Types of plasma jet torches. metal cutting. In the latter type the arc emerges from the nozzle and then returns to the face of the nozzle while the plasma continues to the work; this torch is employed for plasma arc-plating processes, welding, and thermo-chemical studies.

With plasma arc plating various materials, including reinforced plastics, can be coated with a variety of metallic or refractory substances. Metal or ceramic spraying is achieved by the introduction of wire or powder into the torch, so that it passes through the arc and is converted into a plastic or fluid state. The plastic or fluid material is then carried out of the torch by the gas stream and impinges on the component to be coated with such force that a firm bond results.

The plasma arc torch has also been used in advanced research on the metallurgical properties of missile nose cones. When the torch is set up in the wind tunnel as an experimental tool, the plasma arc can simulate speeds up to Mach.20 and reproduce the conditions which a missile would encounter on re-entry into the earth's atmosphere.

There are other applications, allied to welding, for the plasma torch, such as gouging, and it is certain that many more of profound technical importance will appear during the coming years.

Fundamentally, the plasma jet process is a development of the arc principle as applied in electric welding and cutting, and, theoretically, one might expect similar health hazards and possibly additional ones. As it has only recently assumed practical importance, and because its use is likely to be more widespread in industry, we feel that our preliminary observations on some of the health hazards associated with one form of this process are worthy of attention. 


\section{Investigation}

A. Noise.-The torch was being operated in a section of a large factory bay and, although the working area was partitioned off from the rest of the bay, this section had no ceiling. Measurement and analysis of the noise was made at a point slightly to the rear of the torch, corresponding to the position normally occupied by an operator. An illustration of this torch is to be seen in Fig. 3. The

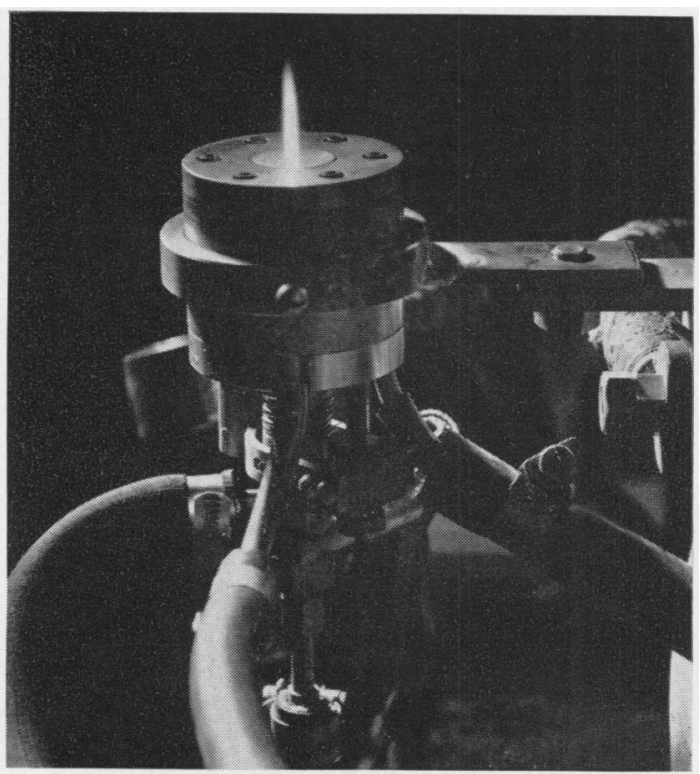

FIG. 3.-Plasma torch used in investigation.

instruments used were a Dawe 1400D sound level meter and a 1410 octave band analyser. The results of these measurements are shown in Fig. 4, together with the damage risk criterion proposed by Burns and Littler (Littler, 1958). A narrow band analysis of the noise, using a Dawe A.F. Analyser, Type 1401D, was made during further tests and this showed that the noise was largely broadband in nature, corresponding to the octave band analysis, and there were no markedly predominant frequencies.

In view of these findings, it was decided to expose three volunteers to the noise for an hour and to determine their temporary threshold shift, using an Amplivox model 61 clinical audiometer. The preexposure hearing tests were carried out on the volunteers when they first arrived at work in the morning and were undertaken in the works surgery, in which the sound levels had been previously measured and found to be: ' $A$ ' scale $46 \mathrm{~dB}$, ' $B$ ' scale $52 \mathrm{~dB}$, and ' $\mathrm{C}$ ' scale 62 to $64 \mathrm{~dB}$ (re 0.0002 dynes/ $\left.\mathrm{cm}^{2}{ }^{2}\right)$. This level of noise is such that the degree of

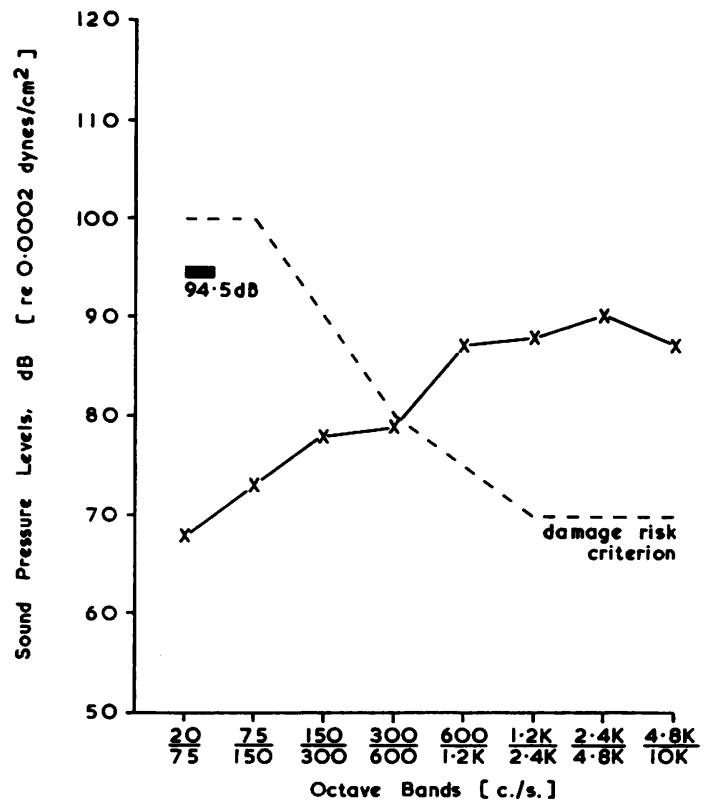

Fig. 4.-Sound levels near plasma torch.

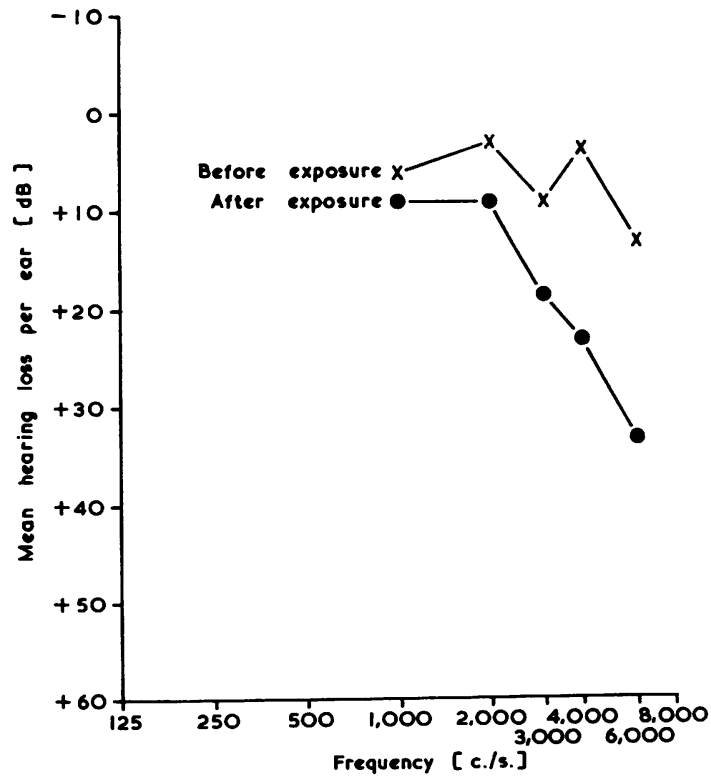

FIG. 5.-Mean hearing loss of three subjects $(a)$ before exposure and (b) after exposure. 
hearing loss measured at $1,000 \mathrm{c} / \mathrm{s}$ is likely to be $5 \mathrm{~dB}$ in error, but higher frequencies should not be affected. The three volunteers were then subjected to exposure to noise from the plasma jet process for an hour, with an intervening interval of 12 minutes during this period for renewal of the gas cylinder; immediately afterwards the audiometric tests were repeated. The mean hearing loss per ear for these subjects, before and after exposure, is shown in Fig. 5. Unfortunately, it was not possible to follow the recovery pattern in all three subjects, but it took one volunteer 48 hours to recover his normal hearing.

B. Air Contamination.-Air sampling for ozone was carried out during one of the periods when noise measurements were being made, and samples were taken in the immediate vicinity of the plasma jet operation. For this study, the torch was operated for two periods of 26 minutes and 41 minutes, with a break of 12 minutes in between to allow for the replacement of a gas cylinder. Argon was used at a flow rate of 6 to $7 \mathrm{cu}$. ft./min., and the power input was approximately $17 \mathrm{~kW}$. Air samples were taken within a radius of $4 \mathrm{ft}$. from the torch by drawing air through bubblers containing $1 \% \mathrm{KI}$ solution, buf-

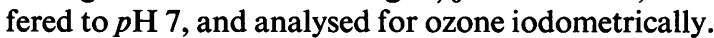
The results of the analyses for ozone were negative, but further chemical treatment of the samples indicated that other air contaminants had been collected, particularly at a position in the direct path of the jet stream, and that they were probably nitrogen oxides.

The process was therefore studied again at a later date with the jet operating with a power input of approximately $20 \mathrm{~kW}$, and an argon supply of $4.5 \mathrm{cu}$. ft./minute. Air sampling for nitrogen dioxide $\left(\mathrm{NO}_{2}\right)$ was carried out at positions in the jet stream by drawing air through absorption trains consisting of a Neale bubbler followed by a fritted glass bubbler, each containing Saltzman reagent (a solution of sulfanilic acid and $\mathrm{N}$-(l-naphthyl) ethylenediamine dihydrochloride in dilute acetic acid). Three periods of sampling were undertaken, of $4 \frac{3}{4}, 5 \frac{1}{2}$, and 4 minutes' duration. The jet was in operation from one minute before the first sampling period until the end of the second period, and from one minute before the third period until the end. For some tests four bubblers were used in series. The observed concentrations were in the range $0 \cdot 1$ to 9.6 p.p.m.

It was ascertained from the scientists engaged on research on the plasma jet process that at no time had they experienced any respiratory symptoms. However, their periods of exposure had been extremely short, never more than one hour, with intervals of minutes of non-exposure during the hour. The workshop in which the experiments had been carried out was reasonably well ventilated. No respiratory ill-effects were experienced by the authors during the investigations.

\section{Discussion}

Measurement and analysis of the noise emitted from the plasma jet process, together with evaluation of the temporary threshold shift in hearing of three volunteers, have demonstrated that the operation of this process presents a hazard to hearing. The scientists engaged on the research were advised to wear ear protection, preferably ear muffs.

The results of air sampling indicated that nitrogen dioxide and possibly other oxides of nitrogen are evolved in concentrations in excess of the maximum allowable concentration for nitrogen dioxide. The fact that such concentrations occurred in the open conditions of a test shop and during short periods of operation of the process suggests that under conditions of poor ventilation, or in confined spaces, and when the process is operated for longer periods, a severe hazard to health might well exist.

Subsequent to the completion of our investigation, two confirmatory papers have been published in the U.S.A. Speicher (1961) has made brief reference to the process and reports noise levels in the range of 80 to $110 \mathrm{~dB}$, according to the method of application of the process. He also reports that concentrations of oxides of nitrogen in excess of 5 p.p.m. may occur within 1 or 2 feet from the jet.

Grimm and Kusnetz (1962) refer to the problems of noise and oxides of nitrogen and also to the radiation emitted from the plasma torch. Their measurements of the ultraviolet radiation confirmed Speicher's view that precautionary measures should be taken to avoid injury to the eyes and skin. They also suggest that the torch may produce radiation within the range of 50 to $10,000 \AA$, which will include part of the $x$-ray band, ultraviolet, visible light, and infra-red.

Although we have no experience of metal and ceramic spraying by the plasma jet process, we think that such operations may well present other health hazards and suggest that they merit study before they are made available for general application. Grimm and Kusnetz refer to instances of exposure to barium and to cases of metal fume fever during plasma torch spraying. They also make suggestions for methods of local exhaust ventilation.

This investigation was carried out when the Occupational Hygiene Service was a department of the Slough Industrial Health Service, whose Medical Director then was Dr. A. Austin Eagger. 
We wish to express our indebtedness to the firm concerned for granting facilities for the investigation, to the members of the staff who collaborated by operating the plasma jet and by acting as subjects for noise exposure tests, and to Mr. M. W. G. Coldham who carried out the chemical analyses.

\section{REFERENCES}

Browning, J. A. (1959). Welding J. (N.Y.), 38, 870.

Gage, R. M. (1959). ibid., 38, 959.

Grimm, R. C., and Kusnetz, H. L. (1962). Arch. environm. Hlth, 4,

Littler, T. S. (1958). Ann. occup. Hyg., 1, 11.

Speicher, H. W. (1961). Arch. environm. Hith, 2, 278. 